\title{
AN INTERNATIONAL SYMPOSIUM ON INSTRUCTION IN THE MECHANICS OF FLUIDS
}

\section{SYMPOSIUM INTERNATIONAL SUR L'ENSEIGNEMENT DE LA MÉCANIQUE DES FLUIDES}

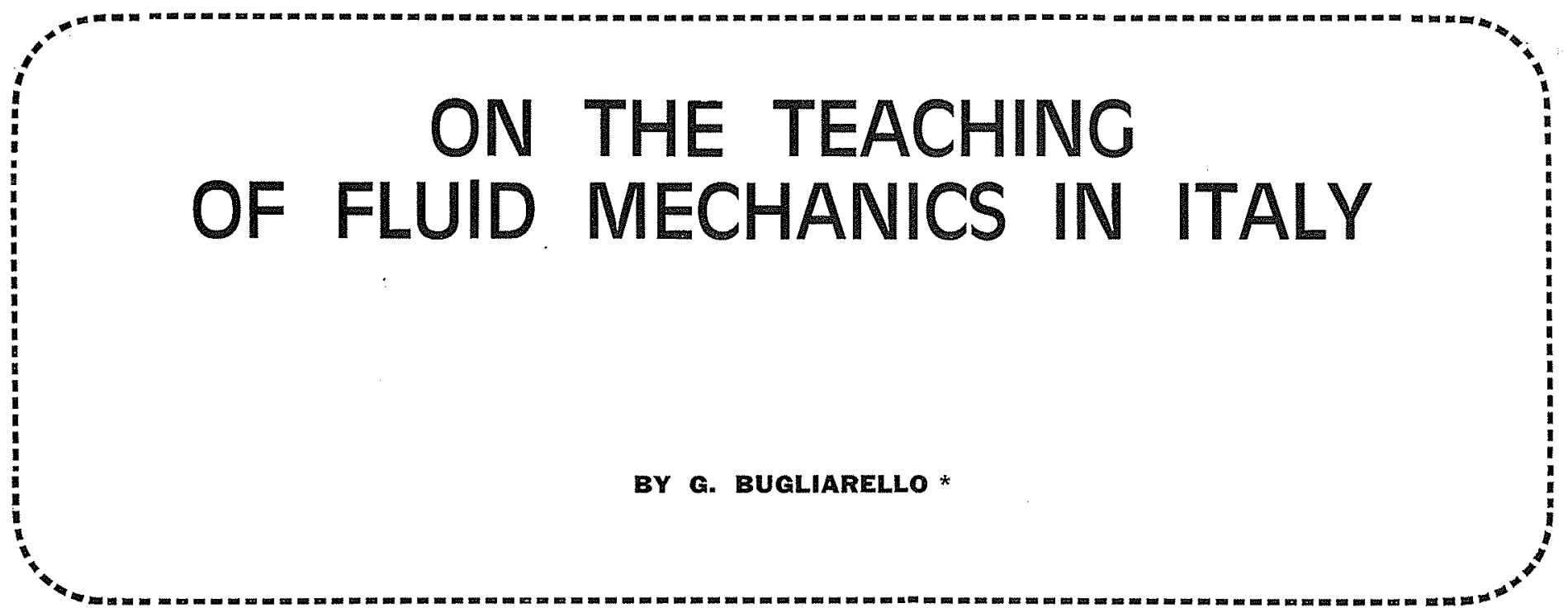

No observer of the contemporary academic scene in Italy can fail to notice the strong influence of tradition in shaping the teaching and research programs in the Italian universities. This is particularily evident in the field of fluid mechanics. Perhaps because of the very brilliance of the Italian school of hydraulics from the fifteenth to the early twentieth century, the basic teaching of fluid mechanics in Italy - compulsory for all engineering students-is entrusted in the universities to the Institutes of Hydraulics and retains, with few exceptions, a considerable hydraulics orientation.

There are at present in Italy twelve universities offering an engineering curriculum. Each engineering student is first exposed to fluid mechanics in a course which is essentially common to all engineering specialities and retains, symptomatically, the name of hydraulics. The characteristics of the course vary naturally with teacher and university, but have several common traits :

1. The arrangement of the subject matter. A typical sequence may cover with varying emphasis hydrostatics, kinematics and dynamics of ideal

* Carnegie Institute of Technology, Pittsburgh, Pennsylvania. flows, viscous flow equations, some notions of turbulence, flow in pipes and channels, flow over weirs and through orifices, ground water flow, and water hammer. Applied hydraulics considerations are stressed, stemming from the fact that, even if taken by students of other specialities, the course remains slanted toward the needs of the hydraulic engineering student. For such a student, the course must serve as preparation for subsequent courses in hydraulic design and sanitary engineering, where there is little opportunity for further study of hydraulic phenomena per se.

2. The organization of the course. Like all courses at Italian universities, the course is annual and consists of about 60 to 70 lecture hours, plus about 40 to 45 hours of recitation, during which, typically, a student may solve from 15 to 20 problems. (As a comparison, the first one-semester course in fluid mechanics at Carnegie Institute of Technology - which is fairly typical for an American university - involves 45 to 50 classroom hours, essentially the same number of hours of recitation or laboratory, plus home-work assignments.) In general, the recitations are of a numeric and applied nature; they are performed in class, and there is no other homework. Only one examination is 
given, at the end of the course-either oral, or both written and oral.

3. The classroom teaching. The course is taught as a series of formal lectures, with little or no dialogue between teacher and student. Contact between student and teacher outside of the classroom is also extremely limited, due to the large size of the classes-sometimes several hundred students. Equally limited, for the same reason, are the contacts between students and the assistants conducting the recitation periods.

4. The laboratory program. As an integral part of the course, this program usually consists of one to five laboratory visits during which the student may be shown, typically, the Reynolds experiment, open channel surface profiles, an application of the momentum theorem, the Bernoulli theorem, the determination of head losses in pipes, and the measurement of turbine efficiency. No experiments are performed, in general, by the students themselves.

5. The lack of exposure of a student to computers, not only in their course, but throughout the curriculum. This is a general weakness of the engineering schools in Italy. Computer are very scarce, and wherever present are operated with closed shop arrangement; only electrical engineering students are likely to have somewhat freer access to them.

Students majoring in fluid-oriented or fluidbased disciplines, such as hydraulic engineering, mechanical, chemical, aeronautical engineering, and naval architecture, are usually exposed to a second course in the area of fluid mechanics. Typically, for the students in hydraulic engineering, this course involves a lighter classroom load than the first, with also more limited laboratory and recitation.

The offering of this course is by no means general, but varies from university to university, according to the curriculum structure of the university, which is generally preestablished and subject to approval by the National Education Council (Consiglio Superiore dell' Educazione). The course must compete with many other subjects for the few slots allowed in the engineering curriculum for electives. When, as a result of these organizational narrows, a second course cannot be offered, frequently the first is strengthened for students specializing in a determined area. Thus, at the University of Rome, Professor Mongiardini teaches a first course of approximately 60 one-hour lectures for the generic engineering student, plus 9 or 10 additional lectures for students who will specialize in hydraulic engineering. The main topics of these additional lectures are dimensional analysis and non-uniform free surface flows. Conversely, at the University of Padua the curriculum has room for a second course ("Applied Hydromechanics") for hydraulic engineering students, covering free surface flows, waves, density currents, solid transport, and hydraulic models.

Students specializing in hydraulic engineering are required to write a thesis which usually consists of a project of an applied or design nature, and only seldom of a basic experimental or theoretical investigation in fluid mechanies. The same situation prevails in mechanical, chemical, and aeronautical engineering, and in naval architecture.

There are, at present, approximately one humdred degrees in hydraulic engineering being granted annually by the twelve universities. These degrees represent--like all the engineering degrees in the country-the culmination of five years of study, of which the first two are spent in a preengineering curriculum, and the last three in an engineering curriculum characterized, as previously mentioned, by a markedly applied orientation.

The Italian university has no graduate school; only exceptionally some specialized courses for graduates are offered by some universilies. For instance, for some years the University of Padua offered a post-graduate course in hydraulics which consisted primarily of the required performance of a certain number of laboratory experiences. Lack of a graduate school limits the offering of courses in fluid mechanics or hydraulics to the one, or at the most, two to which the student can be exposed in the undergraduate curriculum.

Undoubtedly, the structure and subject matter of the teaching of fluid mechanics in Italy are strongly influenced as much by what have been and continue to be the immediate technological needs of the country, as by scientific tradition. Owing to the lack of other energy sources, Italy for the past fifty years has been very heavily engaged in the development of hydropower and of the associated technology. The universities have responded by adressing a considerable portion of the research activities of their Institutes of Hydraulics-which, as already seen, are in a central position with regard to the teaching of fluid mechanics-toward the development of the technology for hydropower. The need for this type of technology continues to be strong even now that nuclear power plants begin to be competitive in Italy with hydropower, because of the hydraulic problems associated with these plants and also on account of the strong activity of Italian consulting and construction combines abroad. Recently, research in the hydraulic institutes has also been oriented to an increasing degree toward the needs of the development program in the south and other underdeveloped regions of Italy-irrigation, drainage, etc. Most of the senior faculty are intimately involved with these programs and devote to them a considerable amount of time and effort, serving as consultants, directors of combines, etc.

Orientation toward such a relatively narrow spectrum of technological problems, and close association with the design and operation of field projects has led to emphasis on research skills of a predominately applied nature, supported by only a narrow program of basic investigations. 'The situation has been possibly accentuated by the fact that universities, being state institutions, are largely removed from that strong competition for 
research grants and other forms of support which in other countries has been a powerful incenlive for the development of new areas of fluid mechanics, new approaches and increasing sophisticated facilities.

The lack of a rich connective tissue of basic research skills and activities, so necessary to the vitality of an academic disciplin, has led in turn to compartmentalization and generally limited innovation in teaching, in terms both of subject matter and methodology.

From conversations with faculty members and students, from the recurring debates in the national press, it is evident that there is in Italy a growing awareness of the need for a reform of the structure and orientation of the entire academic organism, and for a more decisive and fertile science policy.

This is certainly not the place to attempt an analysis in depth of the major obstacles to be overcome in order to achieve in Italy a more stimulating environment for fluid mechanics. The question is extremely difficult and complex, involving deep issues of science policy. However, since nemo propheta in patria, an observer detached from the local academic scene may perform a useful function by stressing what appears glaringly from the outside to be the two pivotal problems : the structure of the faculty and the organization of the curriculum.

The Italian university, similarly to most European ones and unlike the American university, is characterized by single-professor disciplines. Thus, the entire responsibility for the teaching of hydraulics, for deciding on a program of research and supervising it, and also the burden of doing the actual teaching, rests on the shoulders of only one professor per university. In the entire country, therefore, twelve professors of hydraulics are responsible for the first and often only contact of an engineering student with fluid mechanics. Under each professor there is a number of assistants, who are given only a very small degree of autonomy in developing their own research program, as well as in teaching. The salaries for all but full professors are generally low, forcing a faculty member to seek outside work. The chances for a faculty member to achieve full professorial rank at a relatively young age are limited. Also limited are his opportunities for extended and fruitful contacts with institutions in other countries, owing to the lack of a systematic program of leaves of absence. The difficulties of contact with foreign institutions are accentuated by the language barrier and by the general absence of visiting faculty members from other countries-a significant reversal from the traditions of the Renaissance. Excessive statism and unionism, which severely curtail the freedom of a department or an institute to mold the composition of its staff according to its needs, heighten the personnel problems of the university. A hydraulics professor may thus be forced to retain on his staff for a period of up to 10 years an assistant whose productivity has vanished, but who cannot be removed because of government regulations. A serious factor contributing to the inertia of the academic structure is also the lack of a responsive mechanism for the formulation of a national university policy. The National Education Council, the ruling body in these matters, can only approve or deny requests from universities, but cannot give overtly advice or suggest policy-a very cumbersome mechanism for providing guidance, since the formulation of a piece of educational policy may require several passes.

The second major obstacle is the lack of a graduate school. A post-graduate student or junior faculty nember has no opportunity to follow a formal set of courses in order to further specialize in fluid mechanics; neither is he exposed systematically to advanced laboratory techniques. Symptomatic in this respect is the scarcity of expertize. in the use of instrumentation for turbulence measurements, and of other essential electronics instrumentation, and the extremely limited use of computers.

The approaches necessary to overcome these and other accessory obstacles will suggest themselves largely from an effective and dispassionate recognition in depth of the nature of the obstacles. The often-heard opinion in Italy that the present situation is due to a considerable extent to lack of funds for teaching and research in hydraulics and fluid mechanics may be more a rationalization than a strong objective limitation. Even at the present level of expenditures, possibly a great deal could be gained if scientific and technical manpower and funds for research equipment were to be used more efficiently, through measures such as the diversification of the various research institutes-a diversification facilated by the small geographical distances within the country. Rather than having all the laboratories working essentially on the same themes, as is the case today, certain types of research work could be carried out at certain laboratories and other types at others; junior faculty as well as post-graduate students could be rotated among laboratories in a system of apprenticeships.

Coordination between different universities could, furthermore, lead to a singling out of areas of research which could be carried out most effectively-namely areas tailored to the long as well as short range needs of the country and to the facilities and capabilities which are either present or can be more easily developed. If lack of means were to continue to reveal itself as a major obstacle, research in the mathematical aspects of fluid mechanics-following the illustrious examples of Levi Civita and Allievi-could be emphasized, and experimental work carried out only in fewer institutions.

There can be but little doubt that when the long overdue academic reforms are carricd out, they will lead to a rejuvenation of the teaching of fluid mechanics, enabling the Italian university to achieve to the fullest in this field the position to which it is entitled in virtue of its great tradition in mechanics and hydraulics, and of the industry and intelligence of its faculty and students. 